\title{
Pulgar flotante. Descripción y reconstrucción: Gaso clínico
}

\section{Floating thumb. Description and reconstruction: case report}

\section{Revelo J irón, E.*}

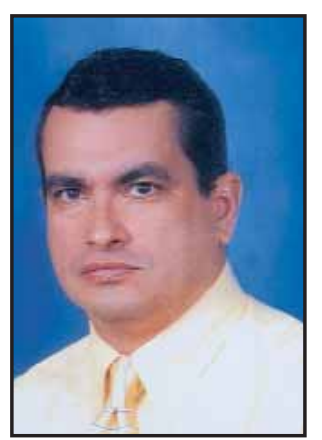

Revelo J irón, E.
Resumen

En este artículo se presenta la descripción clínica y los hallazgos radiológicos de un caso de pulgar flotante parcialmente tratado en su infancia.

Además se plantean las líneas generales a seguir de forma previa al tratamiento ante una malformación congénita del miembro superior y específicamente a nivel de la mano y del pulgar, destacando la clasificación y valoración de los aspectos estético-funcionales. Posteriormente se plantean las conductas quirúrgicas que pueden seguirse y los resultados obtenidos en el caso tratado.
Palabras clave Pulgar flotante. Reconstrucción.

Código numérico 35-35001
Key words

Key words Floating thumb. Reconstruction.

Código numérico 35-35001
This paper deals with the clinical and radiological findings in a case of floating thumb, whose treatment began in the childhood.

The general approach to the upper limb and particularly hand and thumb congenital malformations is outlined, as well as their classification and assessment of the cosmetic and functional aspects.

Finally the different surgical approaches to this pathology are mentioned and the results obtained in the present case are shown. 
Introducción

Las malformaciones congénitas del miembro superior, y específicamente las de la mano, son muy variadas presentándose desde pequeñas anomalías sin grandes problemas estético-funcionales de importancia, hasta las graves malformaciones que pueden volverse invalidantes para el paciente repercutiendo en forma negativa en muchos aspectos de su entorno familiar.

Ante una malformación congénita de la mano hay que identificar tres situaciones:

1.- Clasificación de la malformación

2.- Valoración del aspecto estético

3.- Valoración del aspecto funcional

\section{Clasificación de la malformación}

Para ello es necesario efectuar un examen clínico cuidadoso, completado por estudios radiológicos comparativos entre ambos miembros para determinar el estado de las estructuras óseo-cartilaginosas. El examen clínico completo ayudara a identificar los elementos alterados y por ende, a escoger el tratamiento reconstructivo.

Existen gran variedad de clasificaciones para las malformaciones del miembro superior y de la mano, pero una de las más utilizadas es la elaborada por Swanson (1) quien las enmarca en 7 grupos:

\section{I- $\quad$ Falta de desarrollo}

II- Falta de separación de partes

III- Duplicación

IV- Hipertrofia

V- Hipotrofia

VI- Bridas amnióticas

VII- Anomalías generales

De forma más simplificada, podríamos deducir que estos grupos están enmarcados en malformaciones por exceso, ya sea en número o en volumen, como las polidactilias y macrodactilias; en malformaciones por defecto, es decir falta o ausencias óseas; defecto de longitud; defectos de segmentación o separación; defectos musculares y en ultima instancia las malformaciones por malposición como las clinodactilias y campodactilias.

El pulgar flotante es una patología ubicada en el grupo V de Swanson, y dentro de él en las malformaciones por defecto, producidas por un paro parcial en el desarrollo del área radial del miembro y de la mano (displasias radiales). En este sentido se define como la ausencia parcial o total del primer metacarpiano, lo cual vuelve imposible la función de oposición del pulgar, que se presenta como un dedo de talla reduci-

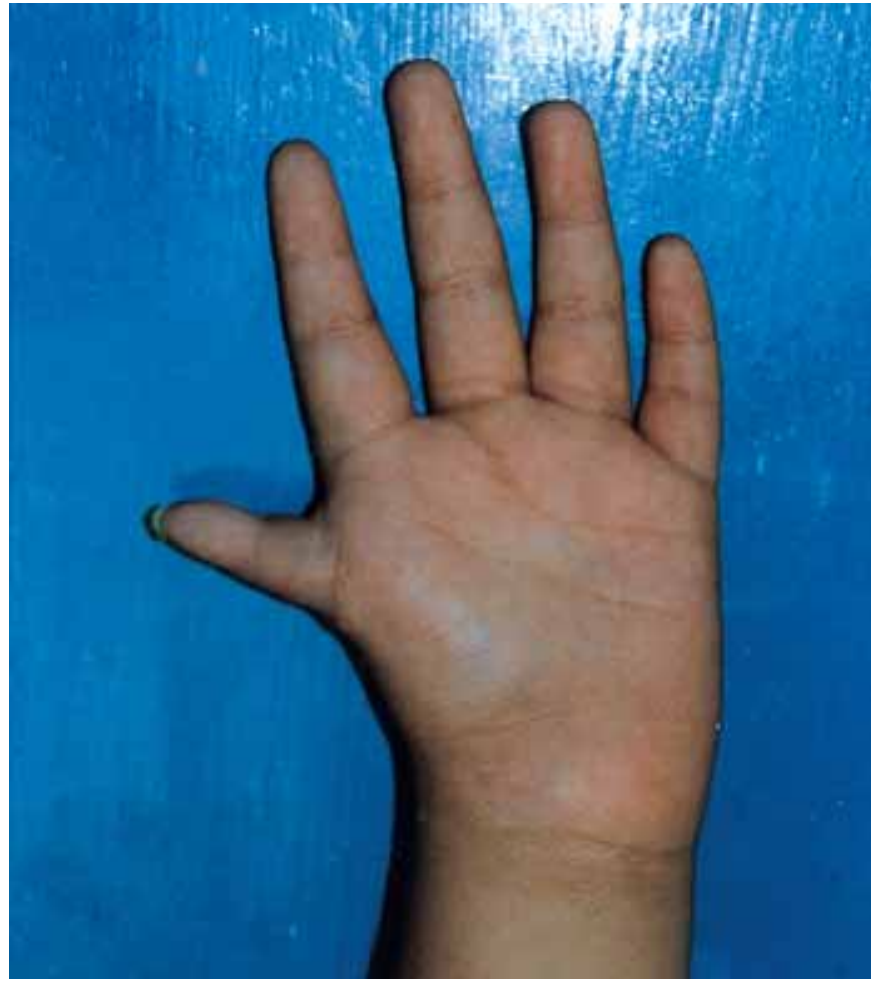

Figura 1: Vista palmar de la mano, en la que se observa la implantación distal del pulgar, disminución en la apertura del primer espacio y ausencia de la eminencia tenar.

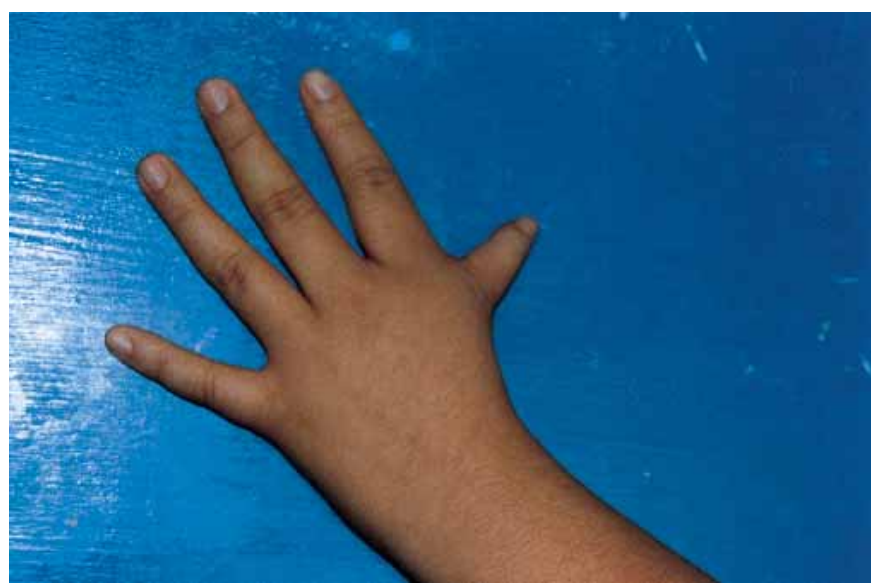

Figura 2. Vista dorsal de la mano; se observa la cicatriz quirúrgica de la implantación efectuada en su infancia y la ausencia del volumen dado por el metacarpiano ausente.

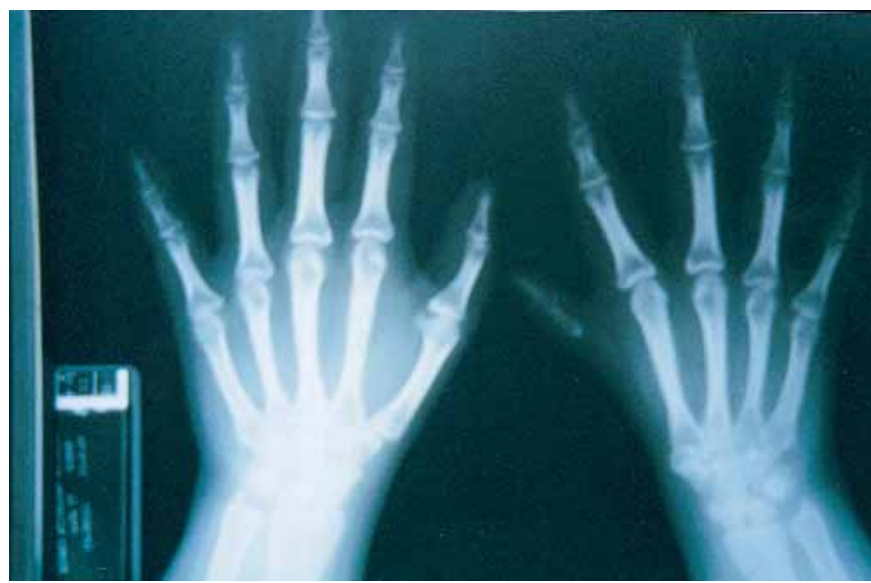

Figura 3. Radiografía simple comparativa de ambas manos: se observa la hipoplasia de las falanges y la ausencia del primer matacarpiano a nivel de la mano izquierda. 


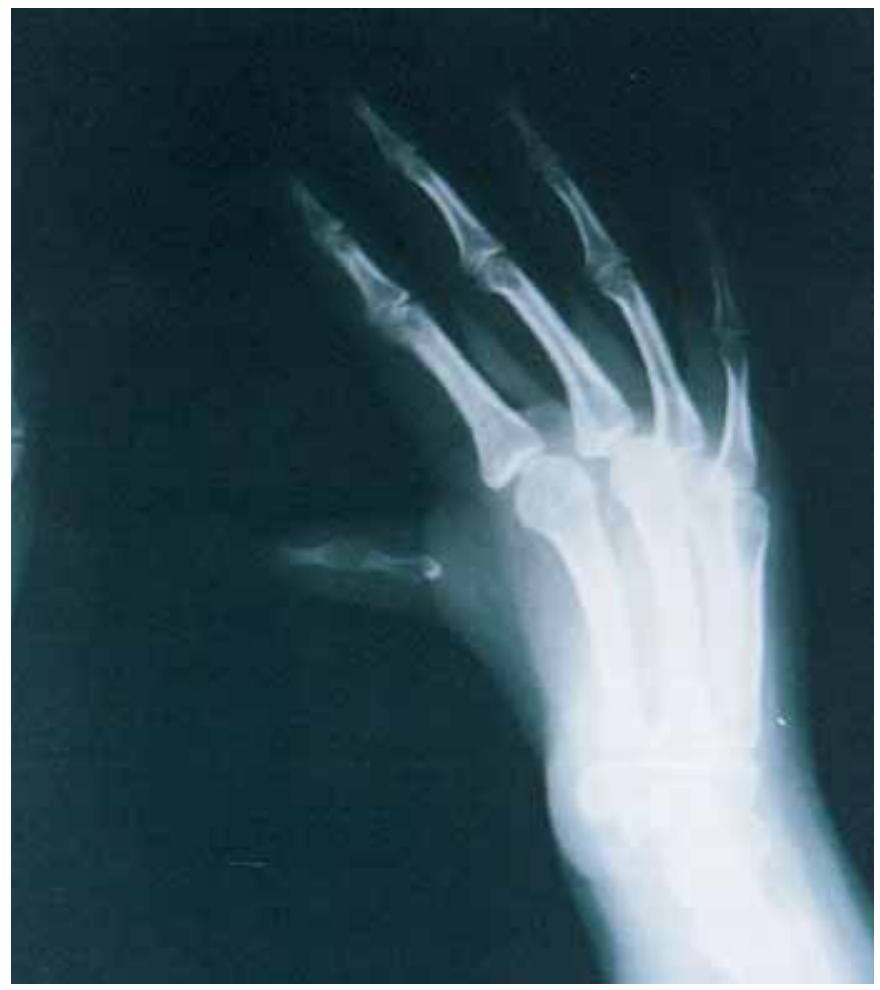

Figura 4. Radiografía simple mostrando la fusión de las falanges hipotróficas.

da con inserción a nivel de la articulación metacarpofalangica del índice, dando a la mano un aspecto estético-funcional primitivo.

En las formas clínicas más graves se encuentra unido al índice por un tubo cutáneo estrecho que solamente porta el pedículo vasculonervioso. Puede haber también ausencia de la eminencia tenar y de los músculos extrínsecos del pulgar, además de ausencia del radio y de la arteria radial, sobreviviendo la mano únicamente con la arteria ulnar.

Blauth (2) presenta una descripción- clasificación de los diferentes tipos de pulgar flotante:

I-Pulgares de apariencia casi normal con aplasia de la eminencia tenar y metacarpofalángica hiperlaxa.

II- Hipoplasia del metacarpiano sin articulación trapecio-metacarpiana ni músculos tenaríanos.

III-El metacarpiano presenta solamente su extremo distal.

IV-El pulgar está reducido a una apéndice en el que el esqueleto está constituido por esbozos de falanges fusionadas y unido al resto de la mano por un cilindro cutáneo que da paso al pedículo vasculonervioso.

\section{Valoración del aspecto estético}

Es en este tipo de patologías donde el aspecto estético toma mucha importancia, influenciado por la demanda de los padres y posteriormente por el niño en edad escolar, que desean una reconstrucción que dote a su mano de una morfología próxima a lo normal; en este sentido es importante explicar a los

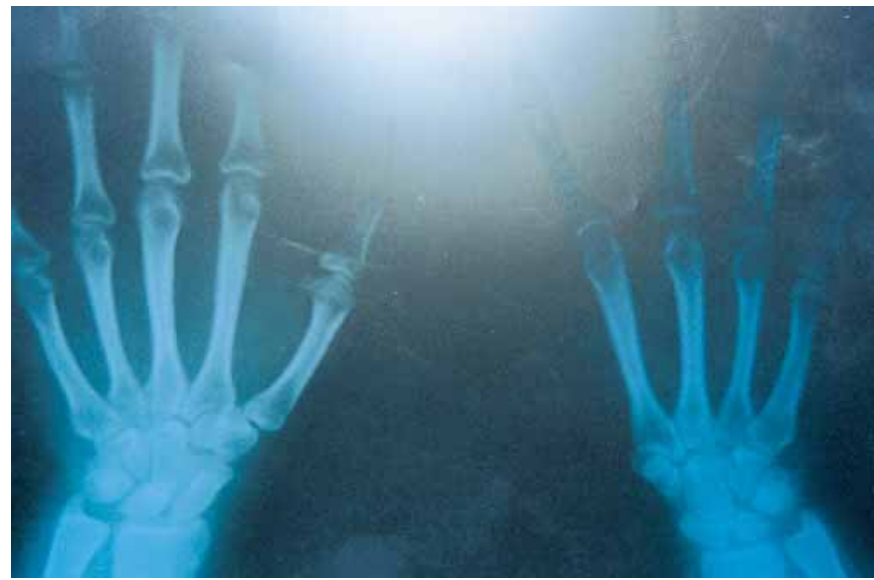

Figura 5: Radiografía simple comparativa de ambas manos: se observa la hipoplasia de los huesos del carpo y del extremo distal del radio.

padres la calidad de los resultados que es posible obtener para evitar decepciones, debido a las expectativas muy ambiciosas que en ocasiones puedan tener.

\section{Valoración del aspecto funcional}

El pulgar es uno de los símbolos que distinguen a la mano humana y le confiere las características para realizar la prensión; esta función necesita, dependiendo de la actividad a efectuar, fuerza y/o precisión; de esta manera, la ausencia o atrofia del pulgar limita la actividad de la mano.Sin embargo, la capacidad de niño para adaptarse a las malformaciones desarrollando habilidades sustitutivas con las partes del miembro intactas es muy alta, sobre todo realizando pinzas dígito-digitales laterales, de ahí que cualquier gesto quirúrgico realizado para mejorar los aspectos estéticos-funcionales debe ser orientado a no alterar esta adaptabilidad y sobre todo a no alterar la capacidad de crecimiento de las estructuras óseas.

\section{Caso clínico}

Se presenta el caso de una joven de 17 años de edad que consultó a nuestro Servicio para lograr una mejoría estético funcional de su dedo pulgar de la mano izquierda. Había nacido con un dedo pulgar pequeño y sin función, unido al resto de la mano a través de un pequeño y delgado tubo de piel; durante la lactancia, había sido tratada en el Hospital Infantil donde le habían únicamente extirpado el área cutánea del pequeño tubo de unión a fin de lograr la implantación directa del apéndice pulgar en la mano.

Cuando acude a nuestra consulta (Fig. 1,2) presenta un pulgar con implantación distal a nivel de la articulación metacarpofalangica del índice, con un primer espacio estrecho, sin capacidad motora de oposición ni flexo-extensión, pero con buena sensibilidad en ambos bordes del mismo. No presentaba eminencia tenar y no se palpaba el primer metacarpiano; además tenía 


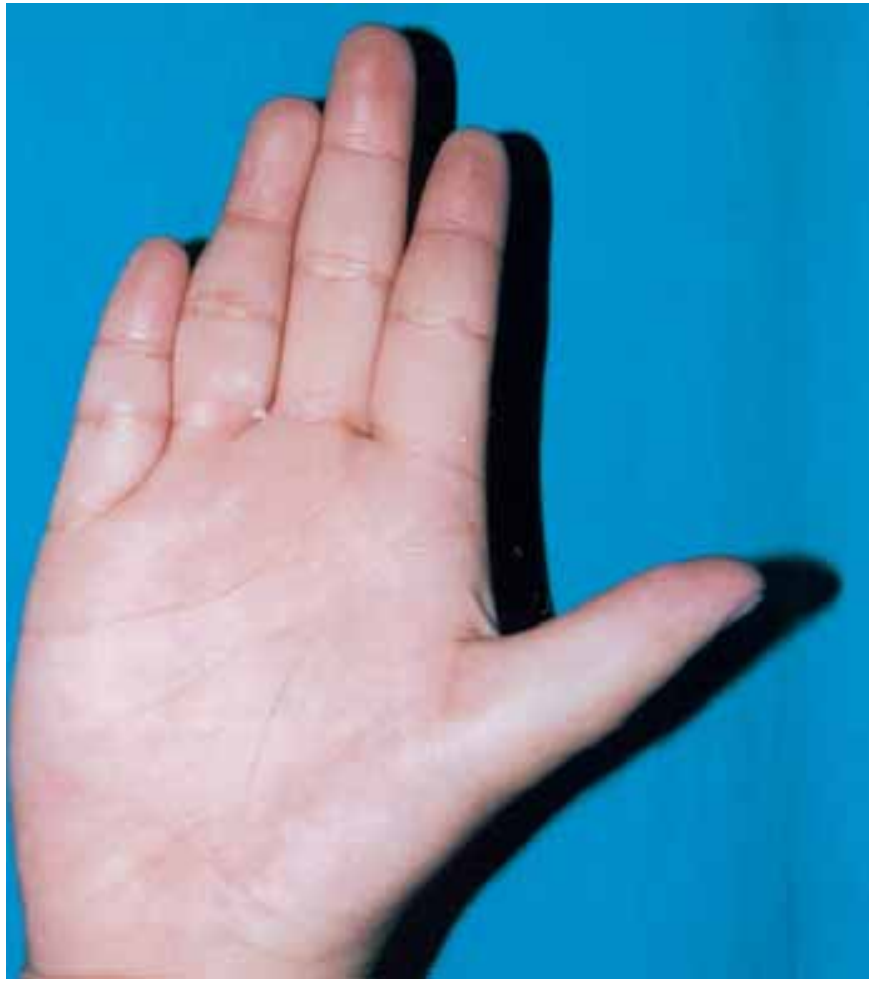

Figura 6: Vista palmar de la mano derecha mostrando la ausencia de pliegues de flexión a nivel del pulgar, primer espacio estrecho y ausencia de la eminencia tenar.

ausencia de pulso radial pero sí se palpaba adecuadamente el pulso cubital. La parte funcional compensatoria la realizaba con alguna dificultad mediante una pinza dígito-digital lateral entre el índice y el medio. Se solicitaron estudios radiológicos (Fig. 3,4) que evidenciaron hipoplasia y fusión de las falanges, agenesia del primer metacarpiano, atrofia del trapecio y resto de huesos del carpo (Fig. 5), así como también atrofia del radio; el estudio con doppler color revelo ausencia de la arteria radial con dilatación compensatoria de la arteria ulnar. Con este examen clínico se diagnosticó un típico pulgar flotante izquierdo parcialmente tratado.

En su mano derecha dominante (Fig. 6) presentaba en el pulgar las siguientes anomalías: primer espacio estrecho, ausencia de los pliegues de flexión, ausencia de la eminencia tenar, imposibilidad para flexionar la articulación metacarpofalángica pero con buena movilidad pasiva de la misma, anquílosis de la articulación interfalángica; a pesar de todo esto había buena función del mismo. El estudio radiológico y con doppler color no evidenciaron anomalías óseas o vasculares. Con estos hallazgos podríamos clasificar el pulgar derecho en el grupo I de Blauth.

No se detectaron otras anomalías corporales congénitas .

\section{Tratamiento y resultados}

$\mathrm{Al}$ reconstruir un pulgar se deben tener bien claros algunos objetivos generales que ayudarán a la funcio-

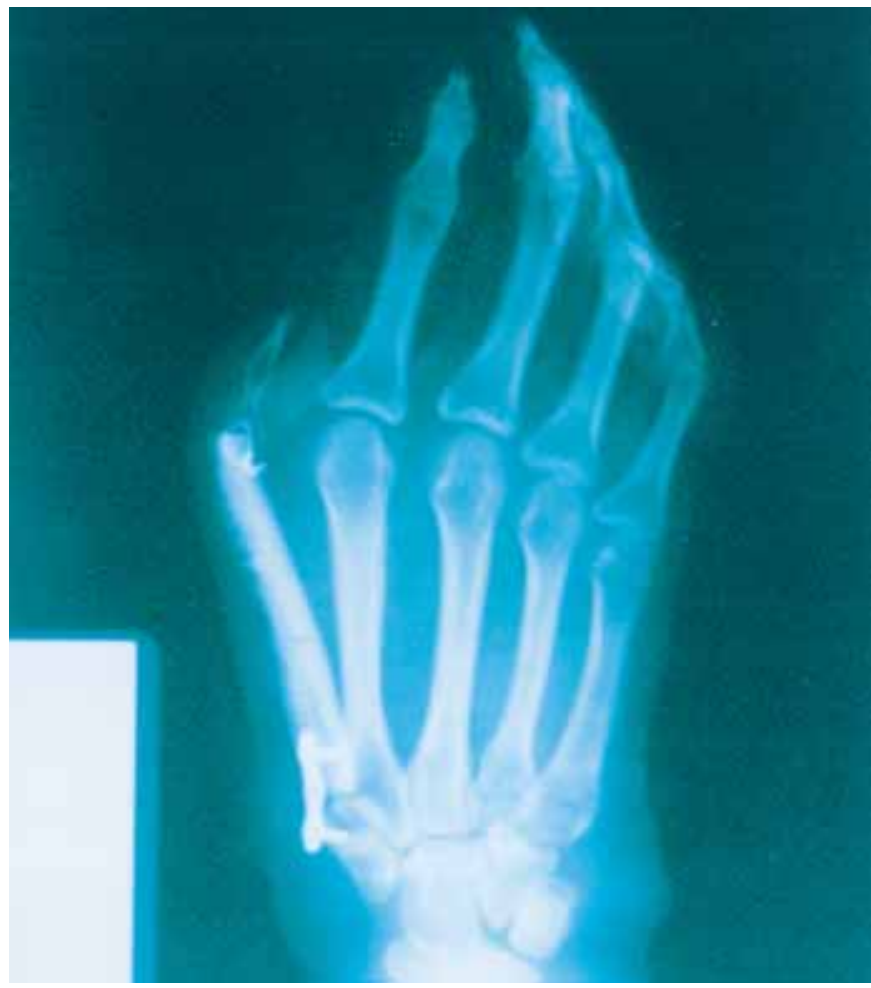

Figura 7: Radiografía simple mostrando el injerto óseo para la confección del neo-metacarpiano.

nabilidad del mismo, como son lograr estabilidad, oposición, sensibilidad, darle una longitud adecuada, darle movilidad en lo posible y un buen aspecto estético.

En la reconstrucción de un pulgar flotante existen dos conductas básicamente opuestas, que deben discutirse ampliamente con los padres y con el paciente si éste se encuentra en una edad de comprender.

Desde el punto de vista práctico se trata de decidir entre una de las siguientes actitudes terapéuticas:

\section{Amputación y reconstrucción:}

La amputación del pulgar flotante conducirá a una aplasia que necesitará una reconstrucción con técnicas microquirúrgicas tales como pulgarización del índice que se realiza con buenos resultados desde $1964(3,4)$, o la transferencia de un ortejo, técnica que conlleva muchos riesgos sobre todo cuando no se tiene un buen entrenamiento en microcirugía $(5,6)$ o no se cuenta con la infraestructura idonea. En teoría, son las técnicas que mejor resultado estético-funcional producen.

\section{Conservación y estabilización:}

Son posibles tres tipos de conducta dependiendo del tipo de patología según la clasificación de Blauth

-Estabilización de la articulación metacarpofalángica.

-Estabilización de la metacarpofalángica más una transferencia de oposición. 


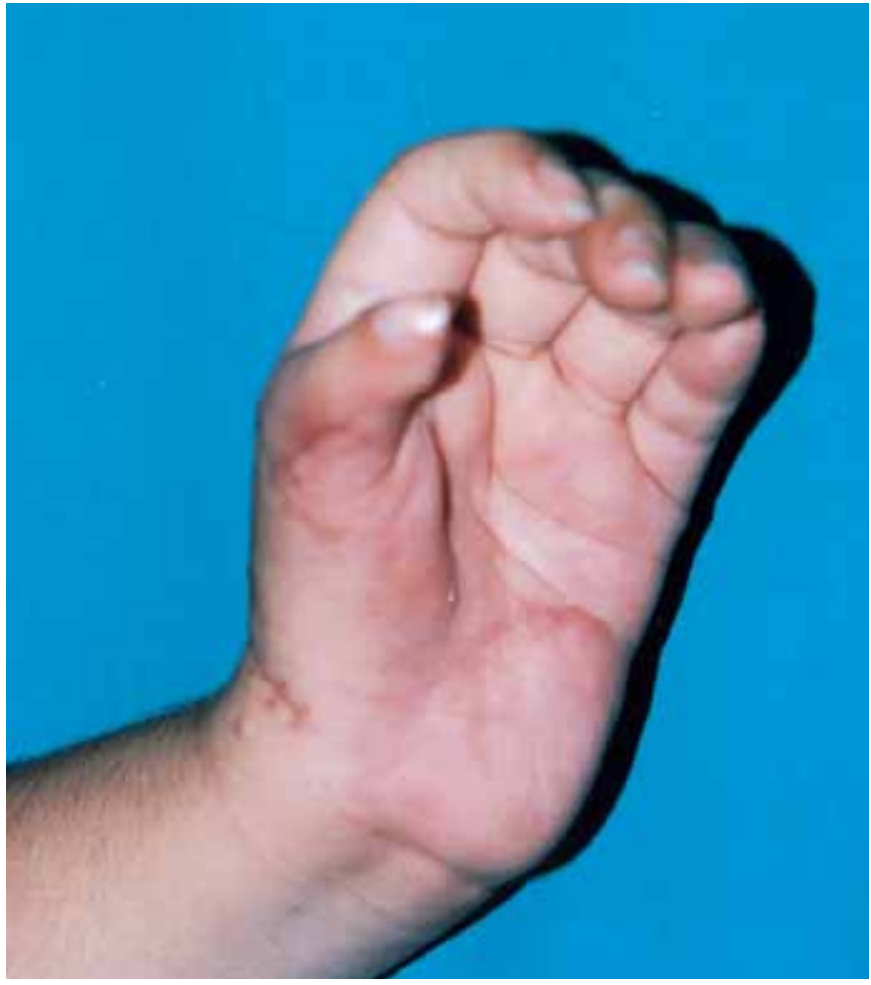

Figura 8: Vista palmar postoperatoria mostrando la oposición del pulgar para la realización de la pinza. Se observa la mejoría estética de la mano al ganar volumen la región tenar.

- Reconstrucción del metacarpiano con una transferencia ósea vascularizada o no.

En nuestra paciente, una vez hecho el diagnóstico e identificados los problemas, se plantearon a la madre y a la paciente las conductas quirúrgicas presentadas anteriormente, pero en definitiva fue sumamente difícil convencerlas de amputar el pulgar vestigial y reconstruirlo con una pulgarización del índice, por lo que se tomó la decisión de reconstrucción y estabilización del metacarpiano.

Debido a que la posibilidad de efectuar, por ejemplo, una transferencia con colgajo óseo del tercio distal del radio nutrido por la rama perforante superior de la arteria ínterósea anterior a flujo retrogrado (7), no era viable por las anomalías vasculares observadas con el doppler, se optó por la toma de un injerto óseo convencional a pesar del riesgo de reabsorción que puede presentarse a largo plazo. Para no cambiar de campo operatorio se cosechó el injerto óseo del olécranon ipsilateral; después se estabilizó a nivel del trapecio vestigial con una miniplaca y a nivel de las falanges con alambre (Fig. 7), logrando darle al neo-pulgar orientación en oposición. Para mantener estable esta posición y evitar futuros desplazamientos se decidió efectuar la transferencia del músculo abductor del meñique para fijarlo al neo-metacarpiano y reforzar o estabilizar la oposición del pulgar, así como para tratar de aumentar el volumen y por ende la estética del área tenar. La cirugía se efectuó con un bloqueo regional bajo torniquete neumático.

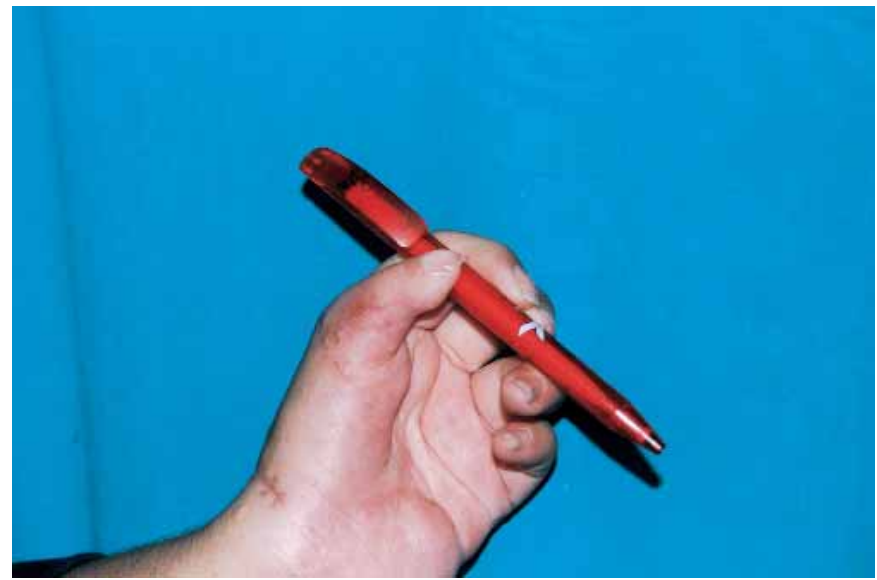

Figura 9: Pinza digital postoperatoria.

No se presentaron complicaciones postoperatorias.

La paciente fue remitida al Servicio de Fisioterapia para el diseño de una ortesis funcional y posteriormente, para el inicio de reeducación funcional.

Psicológicamente la paciente ha respondido de forma positiva ya que ha logrado darle utilidad a su nuevo pulgar y éste ha mejorado en su aspecto estético, aunque no es el aspecto que sus expectativas, normales o no, le hicieron desear (Fig. 8, 9).

\section{Conclusiones}

Ante un pulgar flotante es necesaria la adecuada clasificación del problema, pero sobre todo la identificación de las estructuras alteradas sin obviar las normales para planificar un adecuado tratamiento. También es necesaria la adecuada comunicación con los padres y con el paciente para que asimilen en forma clara el problema y acepten el tratamiento escogido; de esa manera ellos se sentirán satisfechos con los resultados aunque éstos no satisfagan completamente sus expectativas previas.

Si bien es cierto que una conservación del pulgar vestigial más una reconstrucción del metacarpiano y su estabilización no produce los mejores resultados estético-funcionales, sí proporciona una mejoría en la realización de la pinza de prensión y, sobre todo, supone un recurso de rápido tratamiento, con bajo costo y fácil de efectuar.

\section{Dirección del autor}

Dr. Eduardo Revelo Jirón

Paseo General Escalón, Edificio Villavicencio Plaza, Tercer piso, local 13

San Salvador, El Salvador, Centro América

e-mail: eduardorevelojirón@ hotmail.com 


\section{Bibliografía}

1. Swanson A.B. "A classification for congenital limb malformations”. J. Hand Surg., 1976, 1,(8):22.

2. Blauth W., Schneider,Sickert F. "Congenital deformities of the hand. Atlas of their surgical treatment”. Springler-Verlag, 1981.

3. Buch-Gramcko D. "Pollicization of the index finger. Method and results in aplasia and hypoplasia of the thumb". J. Bone Joint Surg., 1964; 53A: 1605 .
4. Campbell D. "Pollicisation.An appraisal". Hand,1969,1:27.

5. Lister G.D. "The role of microsurgery in the reconstruction of congenital deformities of the hand". Hand Clin., 1,3,: 431.

6. O'Brien N.M. "Microvascular great toe transfer for congenital absence of the thumb". Hand,1978,10:113.

7. Weiguo Hu, Martin D., Baudet J. «Reconstruction de la colonne du pouce par les lambeaux osteo-cutanes de l'avant-bras». Annales Chirurgie Plastique Esthetique. 1993, 38(4):381.

\title{
Comentario al trabajo uPulgar flotante. Descripción y reconstrucción: Gaso clínicoı
}

\author{
Dr. J avier Enríquez de Salamanca \\ Jefe de Sección \\ de Cirugía Plástica y Reparadora \\ Hospital «Niño J esús». Madrid. España
}

Presenta el autor la reseña de un caso de hipoplasia de pulgar, atípico por lo tardío y la descripción de la malformación.

El caso clínico es interesante. Las malformaciones de la mano hoy en día se tratan en edades tempranas y no es frecuente ver casos tan tardíos. La resistencia del paciente y la familia a la amputación y reconstrucción refleja fielmente la integración psicológica de las malformaciones de extremidades, fenómeno bien estudiado en los textos clásicos.

No está claro que la hipoplasia de pulgar se deba incluir en el grupo V de la clasificación de Swanson adoptada después por la IFSSH y otros organismos. La mayoría de los autores incluyen esta malformación en el grupo I, interrupción del desarrollo y no en el mencionado $\mathrm{V}$, desarrollo insuficiente. Aunque la distinción es irrelevante desde el punto de vista práctico tiene su importancia desde el académico, embriológico, teratogénico y conceptual.

La descripción de la malformación me resulta difícil de entender. Un pulgar flotante, con el pedículo cutáneo tan pequeño como el que se describe es, al menos en mis manos, imposible de reimplantar en el borde radial de la mano sin lesionar las estructuras neurovasculares. Por otro lado, las imágenes del caso coinciden con un tipo muy determinado de hipoplasia de pulgar, y me resulta más fácil entender que la malformación fuera así desde el principio.

La técnica de pulgarización se menciona como microquirúrgica, pero en realidad se puede hacer sin recurrir a microscopio, sobre todo en un paciente de 17 años.

Coincido plenamente con el autor con la necesidad de valorar con cuidado los gestos quirúrgicos en estos casos, particularmente si son tardíos. En el que nos ocupa creo que la ganancia funcional que se puede obtener ya a estas edades, 17 años, es probablemente muy escasa. Dado que se informa de una mejoría en la pinza la agresión quirúrgica se ve justificada, y he de decir que en ausencia de gesto para abrir la comisura y creación de algún tipo de oposición en mis manos no se habría conseguido la ganancia mencionada, por lo que debo felicitar al autor.

Sin embargo creo se debe advertir a los colegas que no se enfrentan con este problema a menudo, que éste no suele ser el resultado en casos tan tardíos, y que en este tipo de hipoplasia de pulgar la reconstrucción no suele proporcionar ganancia, ni estética ni funcional, por lo que la indicación de cirugía ha de ser muy prudente.

Mi felicitación al autor por el resultado y mi agradecimiento por traer a nuestra revista una malformación de miembro superior. 


\section{Respuesta al comentario del Dr. Enríquez de Salamanca}

Sinceros agradecimientos al Dr. Enríquez de Salamanca por sus comentarios y por sus felicitaciones

Con respecto a los tratamientos tempranos en este tipo de patologías es necesario, como el Dr. Enriquez de Salamanca lo expone, efectuarlos en edades tempranas para resolver los problemas funcionales y estéticos de forma adecuada acordes con el desarrollo del infante; a pesar de tener claro este concepto, en nuestro medio es difícil aplicarlo, muchas veces por problemas socio-económico-culturales de nuestra población y por problemas de cobertura deficiente de nuestros sistemas de salud; es así que por desgracia o por "privilegio" no es raro encontrarnos con estos casos en nuestro hospital en donde atendemos población a partir de los doce años de edad.

Con respecto a la inclusión del caso tratado en el grupo V de la clasificación de Swanson, con lo cual no está de acuerdo el Dr. Enriquez de Salamanca, pienso que es difícil hacer la diferencia entre la ubicación en el grupo I (Interrupción del desarrollo) y el $\mathrm{V}$ (Hipotrofia), ya que entre ambas hay una frontera muy tenue de separación y para evitar esa confusión prefiero utilizar la siguiente clasificación, aunque ésta deje fuera los aspectos que él menciona, malformaciones por exceso, malformaciones por defecto y malformaciones por mala posición, que aunque más amplios y generales dejan más clara la ubicación del problema.

Con respecto a la descripción de la malformación es imposible a estas alturas conseguir datos del expediente medico de la paciente en el hospital infantil en donde fue tratada; sin embargo, al momento de la primera consulta en nuestro hospital, la madre fue categórica en la historia clínica de su hija y no podría haber inventado los datos aportados; en la imagen numero 2 se observa la cicatriz dorsal en la base del pulgar lo cual evidencia esos datos. Para fines prácticos entiendo que el Dr. Enriquez de Salamanca defina esta malformación dentro de las hipoplasias del pulgar, pero al hacerlo está ignorando los datos aportados en la historia clínica. En este sentido Blaunt nos des- cribe y clasifica las diferentes formas de un pulgar flotante cuya condición general para definirlo es la ausencia total o parcial del primer metacarpiano quedando sin apoyo el resto de las estructuras del pulgar; por otro lado el pulgar de la mano dominante sí podría enmarcarse en una hipoplasia del pulgar ya que presenta algunas anomalías pero no hay ausencia del metacarpiano.

Considero que un acto quirúrgico realizado a nivel de la mano en el cual se tenga que efectuar disección de nervios, arterias y venas, aunque no sea necesario efectuar microanastomosis vasculares, constituye una intervención de microcirugía y es mucho más cómodo efectuarla con aumento, al menos con lupas (1).

Fue posible en este caso darle al pulgar la función de oposición pasiva; ésto se logró orientando adecuadamente el neometacarpiano y efectuando una estabilización del mismo con una transferencia del abductor del meñique con lo que además se mejoró, en alguna medida, el volumen y por lo tanto el aspecto de lo que sería la eminencia tenar (2-4), pero hay que tener bien claro, como lo asegura el Dr. Enriquez de Salamanca, que la ganancia estético funcional en estos casos será siempre limitada, sobre todo la parte funcional ya que en el paciente de esta edad es difícil modificar su esquema corporal a nivel cerebral; toda esta situación hay que transmitirla claramente a los padres del paciente.

Le reitero al Dr. Enriquez de Salamanca mis agradecimientos por sus comentarios y felicitaciones.

\section{Bibliografía}

1. Lister G.D. “ The role of microsurgery in the reconstruction of congenital deformities of the hand". Hand Clin., 1985; I ,3: 431

2. Littler J.W., Cooley S.G.E. "Opposition of the thumb and its restoration by abductor digiti quinti transfer". J. Bone Joint Surg., 1963; 45A: 1389.

3. Manske P.R., McCarroll H.R. "Abductor digital minimi opponensplasty in congenital radial dysplasia". J. Hand Surg., 1978; 3: 552.

4. Wissinger H. A., Singsen E.G. "Abductor digiti quinti opponensplasty”. J. Bone Joint Surg., 1977; 59: 895. 